\title{
DEVIR ORGÂNICO, CORPO-PAISAGEM: \\ TRAÇOS DA MULHER E DO ANIMAL \\ EM BEAUVOIR, MENDIETA E COLETTE
}

Andreia A. Marin é Graduada em Filosofia/UFPR e Biologia/USP; Doutora em Ecologia e Recursos Naturais/UFSCar. Docente no Instituto de Educação, Letras, Artes e Ciência Humanas e Sociais/UFTM. Área de Interesse: Filosofia Estética. E-mail: aamarinea@gmail.com

Eduardo Silveira é Graduado em Biologia/UFPR e Doutor em Educação/UFSC. Docente no Instituto Federal de Santa Catarina. Áreas de interesse: Arte e educação, Teatro. E-mail: dudublao@ hotmail.com

\section{Resumo}

Em foco, as tramas que servem de sustentação a um discurso de contenção do animal e da mulher, destacadas de três experiências do feminino: a obra de Beauvoir, que denuncia uma centralidade androcêntrica na representação das diferenças; o escape do feminino na escrita de Colette; a força do devir-orgânico nas imagens da artista plástica cubana Ana Mendieta. Ao final, a denúncia da redução da complexidade da mulher e do animal.

\section{Palavras-chave}

Animalidade. Antropogênese. Estudos animais. Diferença. Mulher.

\section{Introdução}

Animal e mulher: nas raízes do mundo orgânico são cavadas suas definições. Lá, de onde o homem, supostamente, se desprendera para inclinar-se a uma busca de sentido, um algo mais que povoasse seus projetos de existência. $\mathrm{O}$ animal, encerrado em uma negatividade que toma as características pretensamente humanas como referência. A mulher, encerrada em um espaço de subjetivação demarcado pelas intencionalidades masculinas. Antropocentrismo e androcentrismo parecem encerrados na lógica da auto referência e na prática de delimitação do outro.

Várias questões levantadas em pensamentos contemporâneos permitem uma abordagem desses mecanismos de unificação das multiplicidades, e de hierarquização das diferenças, de vários pontos de vista. Entre elas, a discussão sobre o termo genérico “animal" em Derrida, a zona limítrofe entre humano e não-humano em Agamben, a pessoalidade animal no perspectivismo apresentado por Viveiros de Castro, o conceito de mulher subsumido na lógica antropocêntrica em Beauvoir, a crítica à identificação normativa que reforça o conceito de mulher, em Butler, além das reflexões tangenciais que incluem as relações de poder e os processos de subjetivação normalizadora, alvos dos pensamentos foucaultianos e deleuzianos. Trata-se, obviamente, de um tema a ser abordado também pela ética, especialmente quando se evidenciam as tramas discursivas entremeadas nas e pelas relações de poder. De outro ponto, a análise desses mecanismos 
não dispensa a revisão das estruturas básicas do pensamento ocidental, às voltas com uma ontologia que pressupõe a essencialidade do humano, e que se reafirma na busca pelo ser, sistematizada, por exemplo, na ontologia fundamental heideggeriana, alvo das críticas contemporâneas focadas na possibilidade de uma descentralização do humano. A centralidade do humano é evidenciada tanto no pensamento moderno, pela pressuposição de uma consciência sobreposta ao mundo, quanto em abordagens contemporâneas que, mesmo ao tentar contornar tal condição, acabam por readmitir a posição de um ser entorno do qual todos os seres gravitam. Para além desse pensamento, temos um humano, cuja ação, já não é o motor dos acontecimentos. Ele está devolvido às condições de compartilhamento com outros seres, anteriores ao comportamento teórico, constituindo relações de alteridade em mundo já não subsumido nas suas próprias intenções. A esse contorno da perspectiva antropocêntrica, associa-se uma defesa da necessidade de superação de um discurso androcêntrico.

Revisitar Beauvoir, nesse sentido, é ocuparmo-nos de ideias e condições que, se de um lado, podem ser apontadas como ultrapassadas, de outro, forçam a reflexão sobre os resquícios, as reverberações e as permanências de um corpo de representações fundado nas mesmas bases androcêntricas que permearam a história.

Em destaque, nesse texto, um ponto de vista a partir do feminino e com o animal, que exige a compreensão das transformações do pensamento sobre a relação entre viventes humanos e não-humanos. Proponho o destaque de elementos da minuciosa análise de Simone de Beauvoir a respeito da conformação da feminilidade, especialmente no que se refere à construção social do conceito de mulher. Em vários pontos da sua obra $O$ segundo sexo, Beauvoir aproxima a mulher do animal, na descrição do ponto de vista androcêntrico. Apesar de partir do recurso de distinção entre vida e existência, comum à ontologia fundamental, ela o faz denunciando a diminuição do devir orgânico e a valorização do projeto existencial, que lemos em analogia às dicotomias corpo versus mente, animalidade versus ser de razão. $\mathrm{O}$ fato que importa destacar é a forma como ela enxerga uma nítida associação entre vida e mulher e entre homem e existência, resultando a sua inevitável menoridade, já que encerrada nessa dimensão julgada de menor importância. Vemos, aí, o mesmo destino dado ao animal.

Outro aspecto interessante do pensamento de Simone de Beauvoir, algo que repete uma distinção feita entre animal e humano: a mulher, tal qual o animal, assume, em alguns momentos, um estranho duplo que a encerra ao mesmo tempo no destino orgânico, enquanto a lança em uma dimensão mítica, que parece não ser mais que um 
reflexo da necessidade de sentido do projeto existencial androcêntrico. De um lado, a denúncia de uma condição de ser para a reprodução, que encerra a mulher no destino orgânico. De outro, quando analisa os corpos da mulher e do animal sujeitos ao sacrifício ou quando considera a gestação na mulher como algo associável a uma sacralização da vida, ou ainda quando destaca a destinação da mulher aos papéis de sacerdotisas ou videntes, Beauvoir aponta para essa aura de mistérios que marcam seu destino. O mistério que encerra a animalidade parece ser do mesmo teor que aquele em que se permite a transmutação da mulher, permitindo-lhe uma existência extramundana que a libera da restrição da vida orgânica. Essa questão será detalhada no desenvolvimento do texto (item 2).

A condição androcêntrica, assim denunciada por Beauvoir, parece ser também alvo, direto ou indireto, das inquietações identificáveis nas imagens e performances criadas pela artista plástica cubana Ana Mendieta e nos textos produzidos por Colette. Na primeira, uma materialização do ser mulher se dá, imprimindo-a nas paisagens e dando à visibilidade um corpo em compartilhamento com viventes não-humanos e em associação com morte, traindo tanto uma lógica antropocêntrica quando androcêntrica. Em Colette, essa ruptura com a perspectiva androcêntrica está sugerida em uma narrativa que aponta para estratégias de escape da mulher dos esforços de contenção da feminilidade em um projeto existencial masculino, que se coaduna com as reflexões beauvoirianas.

De início, apresentamos breves descrições derivadas das imagens da série Silhueta (1978) de Ana Mendieta. Nas paisagens provenientes do encontro entre narrativas e imagens, a força dos emaranhados entre vida e morte, da relação sagrada entre o corpo e o feminino, onde o devir orgânico da mulher é também extensão ao mundo. Na sequência, as imagens da mulher na escrita de Colette, em A vagabunda, que acena para uma feminilidade que escapa dos domínios existenciais do homem. Ao final, uma síntese reflexiva sobre o antropo(andro)centrismo.

\section{1) Terra, fogo, sangue e morte}

Iniciamos com as impressões das imagens de Mendieta que motivam essa escrita, como se experimentássemos nós mesmos suas ações performáticas.

Sinto meu corpo impregnado na terra. De terra. Trata-se de uma fusão. A força orgânica de um compartilhamento carnal. Vejo-me um corpo-mundo. Inevitável que eu o seja, embora os volteios da representação tenham tentado dissuadir-me disso... 
Decido, deliberadamente, cravar-me no mundo. Invadir sua carnalidade e deixá-lo marcado por minha silhueta de mulher. Organicizo-me com o mundo, pois longe de qualquer ingenuidade pretensiosa, sou dele. Faço-me com ele (Imagen de Yagul, 1973) ${ }^{1}$.

Não recuso a nudez. É ela que me aproxima da natureza. Uma natureza liberdade. Comunhão de seres em sua diversidade constitutiva. A nudez de meu corpo que é plenitude com o mundo. Não posso deixar de sê-lo e encravo minha existência na terra. Sou animalidade encravada no mundo e marco-o de minha silhueta. Torno-me terra e deixo plantas crescerem sobre minha pele. Torno-me planta e invado-me de tronco rijo (Sin Titulo, 1977) $)^{2}$. Torno-me rocha e danço-me de mineral. Torno-me ave e me visto de plumas leves e suaves (Feathers on a woman, 1972) ${ }^{3}$.

A suavidade me leva a desenhar. Uso meu corpo: seu movimento é meu pincel, seu sangue é minha tinta (Blood Sign/Body Tracks, 1974) ${ }^{4}$. É também meu sangue que suja e extravasa-me pelo corpo nu que grita minha condição mundana contra os homens (Rape Scene, 1973) ${ }^{5}$.

Aos poucos, peregrinando de ser em ser, substância em substância torno-me fênix e incendeio-me. $\mathrm{O}$ fogo acaricia minha silhueta, apaga aos poucos meus resquícios e leva aquilo que em mim ainda é transcendência existencial ou consciência. Pacientemente espero ele levar-me e deixar somente cinzas, fumaça e o pó daquilo que outrora fora um eu (Alma Silueta em Fuego, 1975) ${ }^{6}$. Torno-me, de fato, silhueta e conecto-me com a morte. Invado a morte através de seus restos. Brinco com esqueletos. Nossa relação se estabelece em uma proximidade sacrificial. Um abraço de finitude (On Giving Life, 1975) ${ }^{7}$. É também na morte e no sacrifício que me encontro com os animais. Empresto-lhes meu sexo e, em um rito de sangue e morte, comungamos a submissão que nos une (Chicken Piece, 1972) ${ }^{8}$.

\footnotetext{
${ }^{1}$ https://www.sfmoma.org/artwork/93.220

${ }^{2}$ http://greenmuseum.org/c/aen/Images/Ecology/arbol.php

${ }_{3}^{3}$ http://www.learn.columbia.edu/courses/fa/images/large/kc femart mendiet_68.jpg

${ }^{4}$ http://pt.museuberardo.pt/colecao/obras/823

5 http://www.learn.columbia.edu/courses/fa/images/large/kc femart mendiet 69.jpg

${ }^{6} \mathrm{http}: / / \mathrm{www}$. galerie-lelong.com/en/artiste-ana-mendieta/oeuvre-3575-alma-silueta-en-fuego-silueta-decenizas-.html

${ }^{7}$ https://www.alisonjacquesgallery.com/exhibitions/12/works/artworks9102/

${ }^{8} \underline{\text { https://www.alisonjacquesgallery.com/a/exhibitions/12/works/artworks } 9120 /}$
} 
Imersa nesse ritual de morte, desapareço em minha carnalidade e nesse desaparecimento extraio energia vital para tornar-me paisagem. Um corpo-paisagem (Silueta Series, 1978) ${ }^{9}$.

A voz inventada, que pulsa das imagens de Mendieta, nos dá a visibilidade de um corpo-mundo, que jamais pôde sair de sua condição, senão por um esforço de representação. Se o comportamento teórico havia nos dado um corpo compreendido em sua funcionalidade e atribuído a um conceito de corpo humano, corpo de animal, corpo de mulher, a arte de Mendieta contorna a necessidade de uma representação do corpo, na medida em que o dá na sua forma antepredicativa, imerso em um mundo, movimentado pelo devir-orgânico, condição que jamais pode suspender. Dentre os animais humanos, haveria de ser uma mulher a cavar na carnalidade do mundo sua silhueta, ou a abertura de uma vagina, não só reafirmando seu devir orgânico, mas apontando para o humano a ingenuidade de suas pretensões antropocêntricas.

O corpo-paisagem nu age contra as forças de contenção forjadas no homempara-além, no ser destacado dos outros seres, em uma espécie de condenação à consciência suprema, a um eco instransponível das questões pelo sentido. Um corpo de mulher, que como a criança, o selvagem, o animal, jamais ousou esquecer o corpo em busca de uma transcendência existencial. É o mesmo corpo de mulher que se conecta com a morte e sua materialidade. Comunga com esqueletos a finitude e reduz-se, repetidamente, ao pó. Toma dos rituais da morte e do sacrifício a energia vital.

O poeta Manoel de Barros (apud CEZAR, 2008) diz ter conseguido, com a linguagem, arvorizar o homem, mineralizar a árvore, humanizar a pedra, em um esforço de transver o mundo. Pois, ao que parece, Ana Mendieta conseguiu, com a imagem, se transmutar em qualquer vivente, fundir-se na paisagem, pelo poder de um devir orgânico e de uma animalidade que experimentou, também, como mulher, colocando-os nos movimentos poéticos que, tal como a escrita de Manoel, ampliaram o mundo:

Sua Silhueta é redescoberta na natureza; são infinitos possíveis encontros, uma cavidade, uma sombra, um tronco que a artista reconhece e "com os quais" intervém. Sua intenção não é a de se impor à paisagem, mas de se integrar a esta, seguindo um íntimo desejo de compreensão e de considerável fusão. (SACCÁ, 2006, s/p).

De uma mistura intensa entre terra, fogo, sangue e morte, brota a força de uma vida que, escapando dos limites da contenção, ganha potência e instala-se no mundo

\footnotetext{
${ }^{9}$ https://mcachicago.org/Collection/Items/1978/Ana-Mendieta-Untitled-From-The-Silueta-Series-C-1978
} 
como uma provocação, acontecimento. Francischetti (2009, p.4) vê na imagem de uma Vênus Negra que brota da terra, vazia, na série Silhueta, tanto a morte como o vazio potencial a partir do qual pode ser engendrada a criação.

Trotman (2015, s/p) destaca, nas imagens de Mendieta, uma tipologia das formas femininas abstraídas, por meio do qual ela esperar acessar uma força feminina onipresente. São formas cujos braços estão elevados acima da cabeça, aproximando terra e céu, que flutuam na água entre terra e mar, que sugerem uma alma errante.

Todos esses elementos da criação de Mendieta são vistos como movimentos de fuga por um olhar que esteja já atravessado pelas provocações de Beauvoir.

\section{2) Corpo-paisagem, devir-orgânico: diálogos com Beauvoir}

A identificação da mulher com o animal e com uma menoridade em relação ao homem revela o que é o cerne da análise beauvoiriana: uma representação forjada em um princípio de exclusão, negatividade. Ora, é dessa natureza a representação antropocêntrica que coloca o animal como diferença radical do humano, como sua incompletude.

Beauvoir parte da consideração de que "mulher" não é uma algo com existência própria, senão uma representação formada nas bases de uma sociedade machista.

\footnotetext{
Ninguém nasce mulher: torna-se mulher. Nenhum destino biológico, psíquico, econômico define a forma que a fêmea humana assume no seio da sociedade; é o conjunto da civilização que elabora esse produto intermediário entre o macho e o castrado que qualificam de feminino. Somente a mediação de outrem pode constituir um indivíduo como um Outro (BEAUVOIR, 1967, p.9).
}

Essa representação tem, ao que parece, uma duplicidade: a mulher é matriz biológica, estando contida no corpo de uma fêmea humana, mas ao mesmo tempo é deslocada para uma dimensão mítica que, tal qual sua organicidade, ganha algum significado para o homem, servindo de sustentação ao projeto androcêntrico.

Vejamos, inicialmente, a distinção que Beauvoir faz entre vida orgânica e existência. Desconsiderando a ideia hierárquica da evolução que a pensadora carrega, a citação abaixo pode ser proveitosa para compreendermos onde pretende situar o lugar e o sentido dado à mulher:

Um dos traços mais notáveis, quando percorremos os diversos graus da escala animal, é o fato de que de baixo para cima a vida se individualiza; embaixo, ela emprega-se unicamente na manutenção da espécie, em cima ela gasta-se através de indivíduos singulares. Nas espécies rudimentares, o organismo como que se deixa reduzir ao 
aparelho reprodutor; nesse caso, há primazia do óvulo, e portanto da fêmea, posto que o óvulo está principalmente voltado à pura repetição da vida; mas ela não passa de um abdome e sua existência é por inteira devorada pelo trabalho de uma monstruosa ovulação (BEAUVOIR, 1970, p.25).

Um pouco antes dessas considerações, Simone havia dito: “a mulher? É muito simples, dizem os amadores de fórmulas simples: é uma matriz, um ovário; é uma fêmea, e esta palavra basta para defini-la" (BEAUVOIR, 1970, p.25). A mulher está emaranhada nas teias da vida, como base orgânica reprodutora, mas pressente o potencial existencial, ainda que este tenha se voltado, historicamente, ao projeto historial masculino. Em uma nota onde comenta artigo de Michel Corrouges, considera que a mulher não tem existência para-si, sendo considerada apenas uma função no mundo masculino: "a questão está, precisamente, em saber por que se deveria defini-la em relação ao homem" (BEAUVOIR, 1970, p.19).

A mesma questão que se coloca para a animalidade diante do humano: por que se deve defini-lo em relação ao humano. Em um ponto importante de $O$ segundo sexo, Beauvoir destaca fragmento do texto La petite infante de Castille, de Montherlant: "diante da mulher "tem-se o mesmo sentimento que diante de um cavalo, de um touro que se vai enfrentar: a mesma incerteza e o mesmo gosto de medir o próprio poder'”. Vê-se, aí, que a relação não é imediata e sem fundamento, estando ancorada em um interesse/desejo de exercício de poder sobre o outro. É em resposta a esse interesse que se quer na mulher um equilíbrio em uma linha sutil, definido entre o limite para adentrar a existência, evitando perder-se na pura animalidade: "O que há de irritante nas mulheres é a pretensão à razão; quando exageram a animalidade, esboçam o sobrehumano" (MONTHERLANT apud BEAUVOIR, 1970, p.247).

Na medida em que a fêmea humana é encerrada na dimensão da vida, de um devir puramente orgânico, ela está capturada no mundo existencial do homem, uma vez que a vida está subsumida na existência, como seu sustentáculo. A criação no mundo da vida, segundo Beauvoir (1970, p.37), não passa de uma repetição da mesma vida sob formas diferentes, ao passo que a criação no projeto existencial inaugura um modo soberano de ser. É nesse momento que, novamente, a autora aproxima a mulher do animal.

Pela invenção da ferramenta, a manutenção da vida tornou-se para o homem atividade e projeto, ao passo que na maternidade a mulher continua amarrada a seu corpo, como o animal. É porque a humanidade se põe em questão em seu ser, isto é, prefere razões de viver à vida, que perante a mulher o homem se pôs como senhor; o projeto do homem não é repetir-se no tempo, é reinar sobre o instante 
e construir o futuro. Foi a atividade do macho que, criando valores, constituiu a existência, ela própria, como valor: venceu as forças confusas da vida, escravizou a Natureza e a Mulher (BEAUVOIR, 1970, p.86).

Vemos que, por essa distinção entre vida e existência, fica autorizada uma imposição do homem à mulher, seguida de uma conformação dela ao seu projeto. Ainda que a mulher tenha existência, sua função de reprodutora da vida exige uma duplicidade que, durante muito tempo, esteve atrelada ao projeto existencial masculino. $\mathrm{O}$ termo “mulher" compõe-se em uma malha discursiva que, já no seu ponto de partida, exigiu a conformação:

Pondo-se como soberano, ele encontra a cumplicidade da própria
mulher, porque ela é também um existente, ela é habitada pela
transcendência e seu projeto não está na repetição e sim na sua
superação em vista de um futuro diferente; ela acha no fundo de seu
ser a confirmação das pretensões masculinas. Associa-se aos homens
nas festas que celebram os êxitos e as vitórias dos machos. Sua
desgraça consiste em ter sido biologicamente votada a repetir a Vida,
quando a seus próprios olhos a Vida não apresenta em si suas razões
de ser e essas razões são mais importantes do que a própria vida
(BEAUVOIR, 1970, p.85).

Na obra Chicken Piece (1972), Ana aparece nua, em vídeo, segurando uma ave sacrificada, que ainda mantém seus movimentos, de cabeça para baixo. Trata-se, para Schmidt (2010, p.105), de um traço compartilhado pela mulher e pelo animal que demarca a inferioridade em relação ao poder de decisão quanto a sua vida: "Mendieta confunde o significado de sua identidade com o animal, para paradoxalmente reivindicar seu nome, sua capacidade de auto-biografar e auto-afirmar sua identidade feminina". Um caso de sacrifício onde vítima e sacrificante se identificam.

Se a conformação da mulher é uma ação, ainda que não inteiramente esclarecida, para o animal ela expressa-se em um silêncio: "aos animais só restou seu silêncio para nos confrontar" (COETZEE, 2002, p.32). Fonteney (1998), em O silêncio dos animais faz a defesa da possibilidade de movimentos de sentidos na linguagem silenciosa dos animais.

O silêncio dos animais parece permitir, e fomentar, uma rica construção imaginária, o que nos faz encontrá-los em várias construções míticas. Há, ao que parece, uma zona de indeterminação no animal, assim como na mulher, que constitui um mistério, onde o homem tentará adentrar com algum esforço de domesticação. Para ele, a mulher é "fonte confusa do mundo e turvo devir orgânico, mas é também sob esse 
aspecto que ela permite à sociedade que se separou do cosmo e dos deuses, permanecer em comunicação com eles" (BEAUVOIR, 1970, p.192). As mulheres, historicamente, foram porta-vozes dos deuses e das forças da natureza. Atualmente estão travestidas de cartomantes, profetisas, videntes, bruxas. "Quando os homens sentem necessidade de mergulhar de novo no seio da vida vegetal e animal, apelam para a mulher" (BEAUVOIR, 1970, p.193). Não obstante, são os homens quem fazem uso e tiram proveito dos poderes femininos quando, por exemplo, buscam ascensão espiritual através de ritos e bacanais: "No mundo reconquistado pelos homens é um deus masculino, Dionísio, que usurpa as virtudes mágicas e selvagens de Ichtar, de Astarté" (BEAUVOIR, 1970, p.193).

A condição das virgens parece evidenciar ainda mais um natureza feminina que se oculta, numa opacidade própria de uma dimensão não-humana: "próxima ainda do animal e da planta, (...) ela não é nem criança nem adulta; sua feminilidade tímida não inspira o medo e sim uma inquietação temperada. Compreende-se que seja uma das imagens privilegiadas do mistério feminino" (BEAUVOIR, 1970, p.238).

Essa dimensão de mistérios que cerca a existência da mulher é mencionada por Beauvoir quando destaca o papel das feiticeiras:

\begin{abstract}
Ídolo supremo nas regiões longínquas do céu e do inferno, a mulher acha-se, em terra, cercada de tabus como todos os seres sagrados; ela própria é tabu. Em virtude dos poderes que detém olham-na como feiticeira, como mágica; associam-na às preces, torna-se às vezes sacerdotisa como as druidesas entre os antigos celtas... (BEAUVOIR, 1970, p.90).
\end{abstract}

A espiritualização da mulher ganha novos contornos com o cristianismo, comportando uma conciliação entre o devir orgânico e a sacralidade.

\footnotetext{
Vê-se a que ponto a figura da mulher se espiritualizou desde o aparecimento do cristianismo; a beleza, o calor, a intimidade que o homem deseja ter através dela não são mais qualidades sensíveis; em lugar de resumir a saborosa aparência das coisas ela torna-se a alma delas; mais profundo do que o mistério carnal, há em seu coração uma secreta e pura presença em que se reflete a verdade do mundo.
}

Tudo se passa como se o homem desejasse, a um só tempo, a revelação do indeterminado na mulher e sua contenção em um território próprio. Foucault (1999, p.59), em História da sexualidade I, destaca a forma como forças, como as da tradição cristã, incutem a necessidade de uma confissão a partir de pontos diferentes: "parecenos, ao contrário, que a verdade, na região mais secreta de nós próprios, não 'demanda' 
nada mais que revelar-se; e que, se não chega a isso é porque é contida à força, porque a violência de um poder pesa sobre ela".

O homem esforça-se por manter o território feminino, encerrado em seu devir orgânico, mas, ao mesmo tempo, assume a necessidade de inserir a mulher na dimensão existencial e mítica. A mulher o devolve à natureza - "a penetração sexual não é o único modo pelo qual se pode realizar uma apropriação da terra” (BEAUVOIR, 1970, p.198) -, permite que sua animalidade não seja esquecida e que a exerça em uma relação de poder, e ao mesmo tempo, garante o seu equilíbrio com o desconhecido.

Seguramente, em certo sentido, a mulher é misteriosa... Cada um só é sujeito para si; cada um só pode apreender a si unicamente em sua imanência. Deste ponto de vista, o outro é sempre mistério. Aos olhos dos homens a opacidade do para-si é mais flagrante no outro feminino; eles não podem, por nenhum efeito de simpatia, penetrarlhe a experiência singular (BEAUVOIR, 1970, p.302).

Beauvoir destaca ainda a importância do adorno como artifício, estimulado pelos homens, de participação em seu projeto e, ao mesmo tempo, de superação da sua natureza: "a mulher faz-se planta, pantera, diamante, madrepérola, misturando a seu corpo flores, peles, búzios, penas", tentando com isso "esconder a crueza animal de sua carne, de seu odor" (BEAUVOIR, 1970, p.201).

Nas imagens de Silhueta (1978) e nas performances de Mendieta, a mulher está nua ou travestida de uma zoé, como que recusando a conformação de uma biopolítica que conforma seus traços aos projetos existenciais, negando sua nudez, exigindo artifícios pelos quais se possa admiti-la em um projeto existencial, como que mascarando sua animalidade. A silhueta formada pelas mesmas flores, plantas, penas, que serviriam de adorno, é desnudada pelas águas e se dissolve na paisagem. Em Bird Transformation, 1972, ela funde a nudez, explicitando seu sexo, com a animalidade, preferindo, sugerimos aqui, o devir orgânico que a contenção no plano androcêntrico.

Na relação com o animal, o humano sente algo como uma zoofilia, uma atração pelo que ele é como diferença, o que se dá também na relação entre o homem e a mulher. No entanto, se para o afastamento do animal nenhum artifício é requisitado, bastando devolvê-lo à natureza de onde a humanidade já se retirou, o afastamento da mulher exige estratégias de contenção mais sutis.

...trançados, encaracolados, esculpidos, seus cabelos perdem seu inquietante mistério vegetal. Na mulher enfeitada, a Natureza está presente mas cativa, moldada por uma vontade humana segundo o desejo do homem. Uma mulher é tanto mais desejável quanto mais se 
acha nela desabrochada e escravizada a Natureza (BEAUVOIR, 1970, p.201).

É a mesma contenção da natureza que se testemunha na tradição judaico-cristã e em todas as doutrinas que submetem a natureza ao espírito. No interior dessas construções ideológicas, a mulher não está mais restrita à sua biologia e seu corpo ascende como corpo glorioso, avança da animalidade à sacralidade: "a mulher não é mais uma criatura animal e sim um ser etéreo, um sopro, uma luz" (BEAUVOIR, 1970, p.223).

Quando Mendieta vai à morte, não é pelo esforço de um imaginário que associa o sagrado ao suprassensível. As marcas sagradas de Mendieta são feitas pelo corpo e sua finitude. Não faz parte de um ritual de elevação do super-humano, mas a encontramos estendida sobre um cadáver disposto na paisagem. Suas deusas, suscitadas da cultura das regiões míticas que trilhou, em territórios chilenos e mexicanos, estão encravadas na terra, compõem nas Esculturas Rupestres (1981), seres encarnados em compartilhamento com outros seres.

Em um dos filmes produzidos pela artista, o corpo encalha na areia depois de ter boiado no mar e seu rosto surge coberto de sangue. É como que um cadáver, o tema da morte aparecendo em plena extensão, uma outra expressão da vida carnal, do devir orgânico. Os úteros cavados na terra abrigam corpos que parecem apontar para a finitude, são como túmulos, diz Heartney (2004). Nas Silhuetas, no entanto, a expressão da morte parece dar lugar a do nada, do esvaziamento. Novamente em uma performance com a água, a silhueta desenhada com material orgânico se desintegra ao contato com as ondas.

As ressonâncias de um pensamento contemporâneo que parece cavar lugar para a minimização do homem, de sua humanidade, de sua grande consciência, solicitando a superação da metáfora do Ser, encontra expressão nessas imagens de desintegração da existência encarnada. A vida que pulsa no corpo não resiste ao desaparecimento, ao fim, enquanto a existência cavada no suprassensível quer persistir amparada pelo universo de sentidos que não é mais que um recurso humano para o contorno de seus limites. $\mathrm{O}$ corpo de mulher, de Mendieta, volta ao útero-túmulo dando-se à desintegração e carrega, com ele, a existência que jamais pôde dele se desprender.

Morre tal corpo, como um animal. Silenciosamente se entregando ao nada, ao vazio acolhedor de um útero que recebe o que antes lançara à vida. 


\section{3) Corpo-animal, corpo-mulher: devir orgânico e contenção}

É no mesmo substrato - a distinção/ruptura animal-homem - que se articulam a máquina antropogênica e a definição redutora de animalidade a partir da referência do que é o homem. Essa definição de animal que reduz uma ampla variedade de formas de vida em uma categoria forjada na ideia do que é não humano foi detalhadamente discutida e criticada por Derrida. Em O animal que logo sou, Derrida (2011, p.88) usa o termo animot como forma de destacar a ampla variedade de viventes não humanos, reduzida em uma categoria única, tentando recuperar assim a singularidade dos viventes. O antropólogo Viveiros de Castro (1996) também destaca que, para os povos ameríndios da Amazônia, não há termo similar à animalidade como definidor de uma categoria única para os viventes não humanos.

A crítica à ontologia fundamental heideggeriana é citada por pensadores que enfrentam o desafio de recuperar a multiplicidade existente por detrás do termo animal. Recorrentemente sugere-se como ponto de partida a obra Os conceitos fundamentais $d a$ metafísica, onde Heidegger afirma que o animal é pobre de mundo: "o mundo de todo e qualquer animal não é apenas restrito em sua abrangência, mas também no modo de penetração no que é acessível ao animal” (HEIDEGGER, 2003, p.224). Heidegger dá como exemplo a abelha que conhece as características da flor que visita, sem conhecer os estames enquanto estames. É nesse sentido que se destaca a riqueza do mundo humano: "maior em abrangência, mais amplo em penetração, [...] mas também cada vez mais insistente no que concerne à penetração" (HEIDEGGER, 2003, p.224). Nessa análise, Heidegger oferece a caracterização mais comumente citada pelos críticos: a pedra sem mundo, animal pobre de mundo e homem formador de mundo. Agamben (2013, p.82) destaca que, apesar disso, Heidegger refuta a determinação do homem a partir da adição de algo a um simplesmente vivente, como vivente capaz de razão e de linguagem. A investigação da relação homem-animal, no lugar de permanecer focada no que permite distinguir o homem do animal, pode estabelecer como alvo o porquê da necessidade dessa separação. É isso que, em parte, propõe Giorgio Agamben (2013) na sua obra $O$ aberto: o homem e o animal, onde destaca o fato de tudo o que se diz humano ter sido formatado a partir da própria distinção de humanidade operada com a linguagem.

Nomeamo-nos humanos diante da necessidade de comportar, na essência de um ser, tudo que diz respeito a essa forma de operar a razão e de acomodar e conter, em 
suas margens, os traços estranhos, desconhecidos, indesejados, incompatíveis com tal essência. É aí nas margens que, discretamente, experimentamos o mistério, o que não dá pra encerrar na decifração de humanidade, o que não é projeto de existência, o "animal em falta de si-mesmo" (NIETZSCHE apud DERRIDA, 2011, p.15). Da mesma forma como a animalidade não é algo dado, mas fruto de um esforço de ordenação que cava limites para diferentes manifestações de ser, a humanidade é um conceito formalizado em nome da "segurança ingênua do homem" (DERRIDA, 2011, p.20).

O recurso antropocêntrico, que forja a segurança ingênua do humano, parece análogo ao recurso androcêntrico, que cava, na vida imanente da mulher, a segurança existencial do homem. Devir orgânico contido em processos de con(form)ação do animal e da mulher.

\section{4) Corpo que escapa: A vagabunda}

Sidonie Colette escreveu a mulher, romanceando uma vida que pulsa, ao estímulo de sua carnalidade, escapando das forças de adequação aos conceitos.

Beauvoir (1970, p.198) cita a obra La chatte, de Colette, onde um jovem marido fixa seu amor na sua gata predileta, porque "através desse animal selvagem e doce tem uma participação no universo sensual que sua companheira demasiado humana não lhe consegue dar". A separação entre selvagem e humano aí sugerida interessa em nossa análise, especialmente porque ela é citada no entremeio da necessidade humana de dominação da natureza, nesse caso, não conseguida com a mulher e transferida ao animal.

Entre as várias forças de conformação do animal está a sua domesticação, a invenção da fraqueza que mina suas potências e o torna dependente de cuidados. Um dos romances de Colette aponta, já no título, um locus no conceito de mulher reservado às fêmeas colocadas à margem da mulher adaptável: $A$ vagabunda. Nele, Colette ridiculariza as tentativas de fragilização reveladas pela representação da vulnerabilidade implícita no conceito de mulher:

"Está morrendo de tristeza... A tristeza está matando-a..." Se você ouvir um dia frases como estas, não se embeba de piedade, encare-as com ceticismo: mulher alguma jamais morrerá de tristeza. É um animal muito sólido, muito difícil de matar! [...] Para espanto do mundo inteiro, poderá oferecer o exemplo desta perturbadora resistência feminina. (COLETTE, 1971, p.35) 
A força parece não se adequar às qualificações que cabem em um conceito de mulher domesticada. Beauvoir destacara: a força parece estar associada ao projeto existencial masculino. Domesticar a mulher prevê um jogo de poder: enfraquecê-la, positiva-la como ser frágil e vulnerável, a quem a associação a um homem, por meio de uma admissão no seu projeto existencial, parece tornar-se o único ou mais viável caminho; afirmar suas particularidades de mulher, em uma espécie de discurso lisonjeiro, nas quais se inclui a vocação para o cuidado, acenando, de saída, uma função específica no plano existencial. A naturalização dessas estratégias no campo discursivo que sedimenta o conceito de mulher exigirá alguma resistência. A Vagabunda, de Colette, aponta para os prejuízos impostos à mulher no acordo conjugal: "não, não é às traições que me refiro, você se engana. Trata-se da domesticidade conjugal que converte a maior parte das esposas numa espécie de pajem de adultos...” (COLETTE, 1971, p.150).

Curiosamente, se a contenção da feminilidade no conceito de mulher parece destituir-lhe a força, e destiná-la ao devir orgânico, de outro lado, e contraditoriamente, exige uma síntese entre candura e satisfação física. Ao que parece, o devir orgânico está também disciplinado. Sua expressão só pode se dar naquele espaço onde serve à existência. Ela não é a pura animalidade reavivando-se na fêmea humana, mas uma potência geradora adornada por uma aura de sagrado, um corpo preso ao útero capturado pelo esforço de contorno de um vazio existencial e por um instinto propagador da vida. Talvez isso tenha a ver com a confusão de sentimentos testemunhada pela personagem de Colette:

\begin{abstract}
A lembrança daqueles dias de satisfação, de alegria física, traz-me aos lábios, quando me sinto cândida e amputada de tudo o que me fazia uma mulher igual às outras, essa exclamação: "Para sempre!...". Mas há também dias lúcidos em que argumento duramente em meu desfavor: “... Não me venha dizer que está extinta, vazia e leve: o animal de que você se julga livre hiberna, e fortifica-se nesse longo sono...". Em seguida, torno a perder a noção do que fui, no medo de sentir-me, outra vez, um ser vivo... (COLETTE, 1971, p.66).
\end{abstract}

É a vida que está contida. É a animalidade latente, hibernante, da qual a mulher, em questão, não é capaz de livrar-se. Algo como a vida nua, que permanece como potência em meio às teias de conformação.

Isso parece ter a ver, ainda, com o estranhamento manifesto pelos homens, diante de duas mulheres que liberam seus corpos ao pulso erótico. A personagem de 
Colette vê no discurso de um amante, totalmente tomado pela lógica normalizante, uma condenação da experiência homossexual: "de que serviria explicar-lhe?... A seus olhos, duas mulheres enlaçadas serão sempre e nada mais do que um grupo licencioso..." (COLETTE, 1971, p.192). Estivesse em um cenário atual, talvez o discurso admitisse alguma outra reação à imagem, mais permissiva, mais tolerante. Se tal cena estivesse disponível ao próprio fetiche, talvez a postura masculina fosse não só de resignação, mas de perfeita cumplicidade, uma vez que, nessas condições, teriam espaço no seu próprio projeto.

No encadeamento dessas questões, vale citar uma interessante abordagem da obra do poeta Whitman, feita por Martha Nussbaum e apontada por Marim (2014, p.50): o poeta descreve em seus textos os componentes orgânicos, como intestinos, rins, pulmões, que não figura como objeto de prazer no poema lírico, restaurando o interesse dos humanos pelo sangue, por aquilo de que seu corpo é feito; seus poemas sugerem a superação da percepção do corpo da mulher como impuro, associado à origem do pecado, propondo "ver na mulher não apenas a carne como contraposição à razão, simbolizada pelos homens". A liberação dos corpos aos seus próprios devires, a aceitação daquilo de que eles mesmos são feitos e a composição carne-razão-emoção, testemunhada pelo corpo feminino, são também matéria criativa de Mendieta e impulsos de escape na escrita de Colette.

As cenas finais de A vagabunda incluem uma outra imagem, mais comum, mas cheia de significados para o desenho dessas ideias: a mulher compartilha com um outra fêmea animal, sua cachorra, o prazer de estarem momentaneamente soltas, solitárias e dispersas em uma paisagem natural:

Negra como uma trufa, lustrada com a escova e com o trapo de flanela, ela rebrilha ao sol, dona completa do Bosque, que possui por meio de uma infernal barulheira, de roncos porcinos, de latidos, de correrias que revolvem as folhas secas... (COLETTE, 1971, p.37).

De novo, é a paisagem como cenário para os devires, para o simples prazer de estarem anônimas, não nomeadas, para a silhueta e sua decomposição. As paisagens abertas parecem, de fato, abrigar a indeterminação mais que os espaços arquitetados para abrigarem a vida contida. Similarmente, o silêncio parece acolher muito mais amplamente os sem nome e sem conceito que os falatórios, sempre povoados de uma força de conformação. 
Em corpos-paisagens e em silêncios, liberam-se as potências dos in(con)formados que pulsam em mulheres e animais.

\section{Referências}

AGAMBEN, Giorgio. O aberto: o homem e o animal. Trad. Pedro Mendes. Rio de Janeiro: Civilização Brasileira, 2013.

BEAUVOIR, Simone. O segundo sexo 1. Fatos e Mitos. $4^{\mathrm{a}}$ ed. Difusão Europeia do Livro, Paris: Gallimard, 1970.

O segundo sexo 2. A Experiência Vivida. $2^{\text {a }}$ ed. Difusão Europeia do Livro, Paris: Gallimard, 1967.

CEZAR, Pedro. Só dez por cento é mentira: a desbiografia de Manoel de Barros. Brasil, 2008. DVD. Filme longa Documentário (82min).

COETZEE, John M. A vida dos animais. São Paulo: Cia das Letras, 2002.

COLETTE, Gabrielle S. A vagabunda. São Paulo: Abril Cultural, 1971.

A gata. Trad. Cláudia G.Lemos. São Paulo: Difusão Européia, 1960.

DERRIDA, Jacques. O animal que logo sou. Trad. Fábio Landa. 2 ed. São Paulo: Editora Unesp, 2011.

FONTENAY, Elisabeth de. Le silence des bêtes. Paris: Fayard, 1998.

FOUCAULT, Michel. História da Sexualidade I: a vontade de saber. Rio de Janeiro: Edições Graal, 1999.

FRANCISCHETTI, Paula. Algumas questões sobre o feminino e a arte de Ana Mendieta. Revista Estética, São Paulo, v.1, pp.1-7, 2009.

HEARTNEY, Eleanor. Rediscovering Ana Mendieta. Art in America. New York, v.92, pp,139-194, November, 2004.

HEIDEGGER, Martin. Os conceitos fundamentais da metafísica: mundo, finitude, solidão. Trad. Marco Antônio Casanova. Rio de Janeiro: Forense Universitária, 2003.

MARIM, Caroline. Aquilo de que somos feitos: um corpo de emoções. In: BORGES, Maria L.; TIBURI, Márcia (orgs). Filosofia: machismos e feminismos. Florianópolis/SC: Editora UFSC, 2014.

MENDIETA, Ana. Serie Siluetas. Imagen de Yagul (1973). Disponível em: https://www.sfmoma.org/artwork/93.220, Acesso em 20 de junho de 2015. 
Serie Árbol de la Vida. Sin Título (1977). Disponível em: http://greenmuseum.org/c/aen/Images/Ecology/arbol.php. Acesso em 20 de junho de 2015.

Feathers on a woman (1972). Disponível em: http://www.learn.columbia.edu/courses/fa/images/large/kc_femart_mendiet_68.jpg. Acesso em 20 de junho de 2015.

Rape Scene (1973). Disponível em: http://www.learn.columbia.edu/courses/fa/images/large/kc_femart_mendiet_69.jpg . Acesso em 20 de junho de 2015.

Blood Sign \#2 / Body Tracks. Sem Título (1974). Disponível em: http://pt.museuberardo.pt/colecao/obras/823. Acesso em 20 de junho de 2015.

Chicken Piece. (1972). Disponível em: https://www.alisonjacquesgallery.com/a/exhibitions/12/works/artworks9120/ . Acesso em 20 de junho de 2015.

Alma Silueta en Fuego. Silueta de Cenizas. (1975). Disponível em: http://www.galerie-lelong.com/en/artiste-ana-mendieta/oeuvre-3575-alma-siluetaen-fuego-silueta-de-cenizas-.html. Acesso em 24 de maio de 2018.

On Giving Life. (1975). Disponível em: https://www.alisonjacquesgallery.com/exhibitions/12/works/artworks9102/ . Acesso em 20 de junho de 2015.

Silueta Series. Sin Título. (1978). Disponível em: https://mcachicago.org/Collection/Items/1978/Ana-Mendieta-Untitled-From-The-

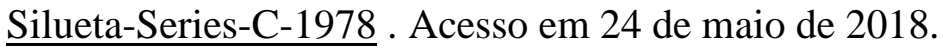

SACCÁ, Lucilla. Corpo em movimento. Nossa América: Revista do Memorial da América Latina, São Paulo, v.22, 2006.

SCHMIDT, Elisa. Ana Mendieta - Cenas sacrificais entre o humano e o animal. Revista Da Pesquisa, UDESC, Florianópolis/SC, n.7, pp.103-111, ago2009-jul2010.

TROTMAN, Nat. Silueta Muerta. Collection online. Guggenheim Museum. New York, 2015. Disponível em: http://www.guggenheim.org/newyork/collections/collection-online/artwork/5216, acesso em 20 de junho de 2015.

VIVEIROS DE CASTRO, Eduardo. Os pronomes Cosmológicos e o perspectivismo ameríndio. Maná, Rio de Janeiro, v.2, n.2, pp.115-144, 1996. 


\title{
BECOMING-ORGANIC, BODY-LANDSCAPE: TRAITS OF THE WOMAN AND OF THE ANIMAL \\ IN BEAUVOIR, MENDIETA, AND COLETTE
}

\begin{abstract}
The discourse of restraint of the animal and the female is addressed through three experiences of the feminine: the work of Beauvoir, who denounces an androcentric centrality in the representation of differences; the escape of the feminine in Colette's writing; and the force of becoming-organic in the images of the cuban artist Ana Mendieta. It concludes by denouncing the reduction of the complexity of the woman and the animal.
\end{abstract}

\section{Keywords}

Animality. Anthropogenesis. Animal studies. Difference. Woman. 